\title{
A masquerading mass: an unusual presentation of IgG4-related systemic disease with tubulo- interstitial nephritis
}

\author{
${ }^{1} \mathrm{~B}$ Quinn, ${ }^{2} \mathrm{~J}$ Harty, ${ }^{3} \mathrm{~W}$ Habeichi \\ ${ }^{1}$ Foundation Year 2 doctor; ${ }^{2}$ Consultant Nephrologist; ${ }^{3}$ Specialist registrar, Daisy Hill Hospital, Newry, Northern Ireland, UK
}

\begin{abstract}
IgG4 tubulointerstitial nephritis (IgG4-TIN) is the most common form of IgG4 renal disease. When IgG4-TIN is accompanied by other systemic manifestations the disease is known as lgG4-related systemic disease (lgG4-RSD). IgG4-RSD is well recognised in the form of tubulointerstitial nephritis (IgG4-related TIN) and may present with renal failure by mimicking neoplasms (tumefactive lesions) or with both features. We describe a case of IgG4-RSD initially presenting as a submandibular mass and subsequently presenting two years later with secondary infiltration of the kidney causing tubulointerstitial nephritis. This case highlights the importance of recognising IgG4-RSD as a non-malignant disease with presentations having commonly shared features including tumour-like swelling of involved organs and its ability to mimic many systemic diseases. In the majority of patients it can be treated successfully with corticosteroids.
\end{abstract}

KEYWORDS chronic sclerosing sialadenitis, IgG4-related systemic disease (IgG4RSD), Küttner's tumour, tubulointerstitial nephritis

DECLARATION OF INTERESTS No conflict of interest declared.
Correspondence to J Harty

Daisy Hill Hospital Renal Unit

5 Hospital Road

Newry BT35 8DR

Co. Down, Northern Ireland, UK

tel. $+44(0) 2830835035$

e-mail john.harty@southerntrust. hscni.net
IgG4-related systemic disease (IgG4-RSD) is a relatively new clinical disease; it was first proposed in 200 I by Hamano et al. who reported it as a case of autoimmune pancreatitis with high tissue infiltration levels of IgG4.' Many organs and tissues demonstrate tissue infiltration with a predominance of $\lg G 4$-positive plasma cells and $\mathrm{T}$ lymphocytes. IgG4-RSD causes fibrosis and a deposit of connective tissue within the affected organ, for example the submandibular gland (chronic sclerosing sialadenitis - Küttner's tumour), the kidneys (tubulointerstitial nephritis) and membranous glomerulonephritis (MGN). ${ }^{2}$

Many patients may have unidentified disease dormant within a particular organ for many years, while others may present sub-acutely with major organ damage. Multiorgan disease can therefore present fortuitously or manifest over months to years. Elevated serum and tissue levels of lgG4 are useful markers in helping to diagnose IgG4 disease. However, histopathological features are required to confirm a diagnosis of IgG4-RSD. ${ }^{3}$

\section{CASE REPORT}

Three months after a simple tooth extraction, a 54-yearold male presented to his general practitioner with a painless mass in the right anterior triangle of his neck, with a second mass developing within several days. Both masses were firm, painless and approximately equal in size. The patient was asymptomatic and had no difficulty eating or swallowing during his assessment. He was otherwise healthy, had a normal body mass index and

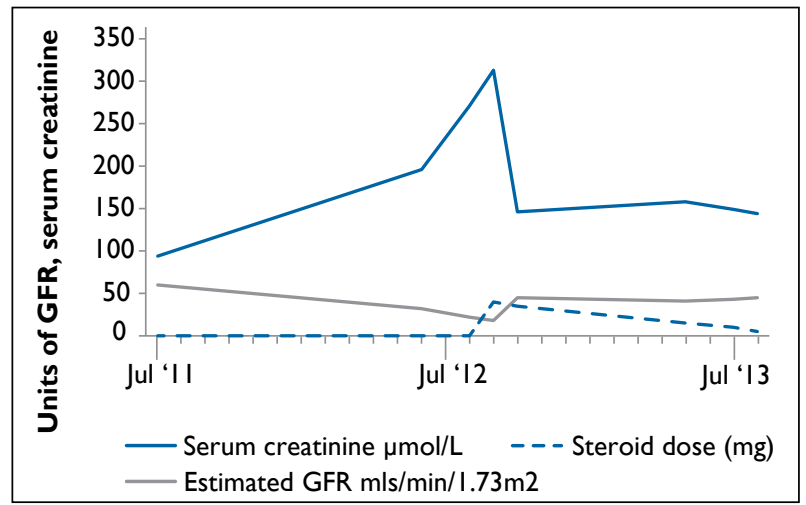

FIGURE I Serial serum creatinine $(\mu \mathrm{mol} / \mathrm{L})$ and estimated GFR $\left(\mathrm{ml} / \mathrm{min} / \mathrm{l} .73 \mathrm{~m}^{2}\right)$. Corticosteroid therapy was commenced two years after the patient's initial presentation.

was a non-smoker who did not consume alcohol.

Assessment by the oral maxillo-facial surgical department found symmetrically enlarged, well-defined, firm nontender, non-fluctuant lesions in the submandibular triangles $(5 \mathrm{~cm}$ right and $3 \mathrm{~cm}$ left). On manipulation, clear saliva was expressed from both parotid and submandibular gland ducts. The expression of saliva from the right submandibular gland was more indolent than on the contralateral side.

An ultrasound of the right submandibular salivary gland found no obvious duct dilatation. An ultrasound-guided fine needle aspiration was performed of the right submandibular gland only as it was felt that both glands 


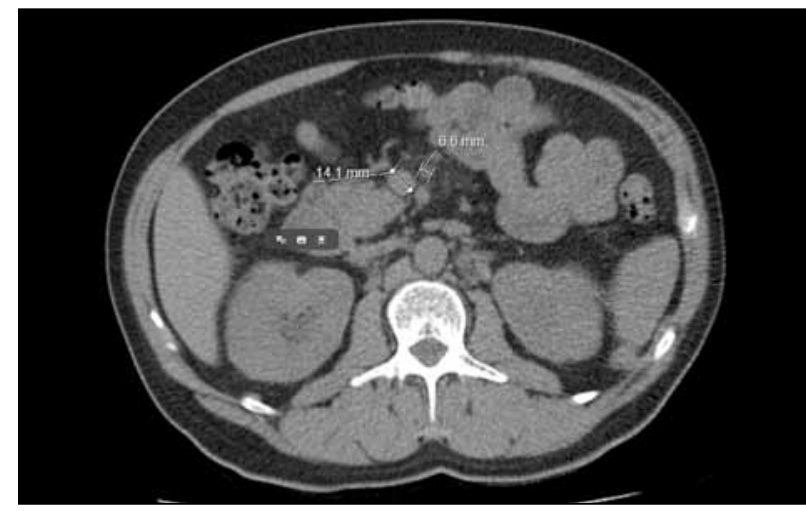

FIGURE 2 Mesenteric lymphadenopathy (arrow) can be seen in the upper abdomen with nodes measuring up to $8 \mathrm{~mm}$ in short axis. No hydronephrosis was found and there were no renal, ureteric or bladder calculi.

would have the same pathology. Histological features were consistent with a diagnosis of chronic sclerosing sialadenitis (Küttner's tumour). Immunohistochemical staining was not performed on the salivary biopsy. The patient was treated with conservative management and reviewed twice yearly by the maxillo-facial team.

Two years after the initial presentation, a routine biochemical screen noted that the patient's creatinine level of $94 \mu \mathrm{mol} / \mathrm{L}$ had increased to $3 / 2 \mu \mathrm{mol} / \mathrm{L}$ in 14 months, with a corresponding decrease in estimated glomerular filtration rate (eGFR) from normal $>60 \mathrm{ml} /$ $\mathrm{min} / 1.73 \mathrm{~m}^{2}$ ) to $18 \mathrm{ml} / \mathrm{min} / 1.73 \mathrm{~m}^{2}$ (Figure I). The total protein/creatinine ratio two years after the initial presentation was $125.6 \mathrm{mg} / \mathrm{mmol}$ (normal range $0-0.14$ ), with an estimated 24-hour leakage equivalent of $1.105 \mathrm{~g}$ (normal range $0-0.14$ ).

The patient was subsequently referred for an urgent nephrology assessment. On clinical examination, both submandibular salivary glands were found to be enlarged and non-tender. There was no abdominal or flank tenderness nor any palpable masses. An ultrasound of the renal tract was normal. An unenhanced volume computed tomography scan of the renal tract found no evidence of renal obstruction. However, mesenteric lymphadenopathy was present in the upper abdomen, with nodes measuring up to $8 \mathrm{~mm}$ (Figure 2). Liver function test and serum calcium were normal. Urinary Bence Jones protein, plasma electrophoresis, including a comprehensive renal vasculitic and antibody screen, identified high lgG levels at $43.70 \mathrm{~g} / \mathrm{L}$ (normal range 6-16) (Table I).

A ultrasound-guided biopsy of the left kidney showed tubulo-interstitial inflammation. Plasma cells were prominent within this infiltrate and there was evidence of tubulitis. The inflammation was associated with an exuberant fibrosing reaction within the interstitium which spilled out into the overlying capsule. Light microscopy identified changes consistent with sclerosing tubulo-
TABLE I A comprehensive renal vasculitic and antibody screen found high $\operatorname{lgG}$ and $\lg \mathrm{G} 4$ levels at $43.70 \mathrm{~g} / \mathrm{L}$

\begin{tabular}{|l|l|l|}
\hline Marker & Result & Reference \\
\hline Complement C3 & $0.5 \mathrm{~g} / \mathrm{L}$ & $(0.75-1.65)$ \\
\hline Complement C4 & $0.04 \mathrm{~g} / \mathrm{L}$ & $(0.14-0.54)$ \\
\hline C-ANCA & negative & \\
\hline P-ANCA & negative & \\
\hline ANCA (atypical) & negative & \\
\hline Rheumatoid factor & $<10 \mathrm{IU} / \mathrm{ml}$ & $(0-0.14)$ \\
\hline Anti ds DNA antibody & $<\mathrm{I} \mathrm{IU/ml}$ & $(0-4)$ negative \\
\hline Anti chromatin antibody & $<0.2 \mathrm{Al}$ & $(0-0.9)$ \\
\hline Anti ribosomal P antibody & $<0.2 \mathrm{Al}$ & $(0-0.9)$ \\
\hline Anti RO 52 antibody & $<0.2 \mathrm{Al}$ & $(0-0.9)$ \\
\hline Anti 60 antibody & $<0.2 \mathrm{Al}$ & $(0-0.9)$ \\
\hline Anti LA antibody & $<0.2 \mathrm{Al}$ & $(0-0.9)$ \\
\hline Anti Sm antibody & $<0.2 \mathrm{Al}$ & $(0-0.9)$ \\
\hline Anti Sm/RNP antibody & $<0.2 \mathrm{Al}$ & $(0-0.9)$ \\
\hline Anti RNPA antibody & $<0.2 \mathrm{Al}$ & $(0-0.9)$ \\
\hline Anti RNP 68 antibody & $<0.2 \mathrm{Al}$ & $(0-0.9)$ \\
\hline Anti SCL 70 antibody & $<0.2 \mathrm{Al}$ & $(0-0.9)$ \\
\hline Anti Jo-I antibody & $<0.2 \mathrm{Al}$ & $(0-0.9)$ \\
\hline Anti centromere B antibody & $<0.2 \mathrm{Al}$ & $(0-0.9)$ \\
\hline PR3 - ANCA & $<0.2 \mathrm{Al}$ & $(0-0.9)$ \\
\hline MPO ANCA & & \\
\hline Anti GMB antibody & & \\
\hline Total protein & $91 \mathrm{~g} / \mathrm{L}$ & $(60-80)$ \\
\hline IgG & $43.70 \mathrm{~g} / \mathrm{L}$ & $(6.0-16)$ \\
\hline IgA & $\mathrm{I} .34 \mathrm{~g} / \mathrm{L}$ & $(0.8-4)$ \\
\hline IgM & $0.69 \mathrm{~g} / \mathrm{L}$ & $(0.5-2)$ \\
\hline $\begin{array}{l}\text { Serum protein } \\
\text { electrophoresis }\end{array}$ & $\begin{array}{l}\text { none } \\
\text { detected }\end{array}$ \\
\hline Abbreviations: ANCA: anti-neutrophil cytoplasmic antibody; Ig: \\
immunoglobulin; GMB: glomerular basement membrane. \\
\hline
\end{tabular}

interstitial nephritis, with staining for kappa and lambda light chains showing a polyclonal plasma cell population with no evidence of light chain restriction. Considerable numbers of the plasma cells were positive for lgG4.

The patient was commenced on prednisolone $40 \mathrm{mg}$ per day (Figure I). Following regular clinical reviews, he reported an improvement in general well-being and, in particular, noted a significant reduction in the size of his salivary glands. Steroids were reduced in $5 \mathrm{mg}$ weekly decrements down to a dose of $20 \mathrm{mg} /$ day. Steroids were then reduced by $5 \mathrm{mg}$ every 2 weeks down to $10 \mathrm{mg} /$ day. Subsequent reduction was by 2.5 $\mathrm{mg} / \mathrm{month}$ down to a maintenance dose of $5 \mathrm{mg} /$ day. After six months and on a dose of $5 \mathrm{mg}$ bloods, he had a normal serum lgG level of $14.67 \mathrm{~g} / \mathrm{L}$, with an $\operatorname{lgG} 4$ level of $0.32 \mathrm{~g} / \mathrm{L}$, creatinine of $132 \mu \mathrm{mol} / \mathrm{L}$ and eGFR of $50 \mathrm{ml} / \mathrm{min} / 1.73 \mathrm{~m}^{2}$. The protein/creatinine ratio was $8.6 \mathrm{mg} / \mathrm{mmol}$ with an estimated 24-hour equivalent protein leakage of $0.076 \mathrm{~g}$. 


\section{DISCUSSION}

lgG4-RSD is a multi-system condition that can infiltrate and alter the normal functioning of several organs, a feature common with other disease processes such as lymphomas and sarcoidosis. While IgG4-RSD and other similar conditions manifest with strikingly similar symptoms and dysfunction in many organs, it is accepted that there are histolopathological features unique to IgG4-RSD allowing for its differentiation and diagnosis.

To date no definitively agreed international guidelines exist for the diagnosis of IgG4-RSD. However, hallmark findings for a diagnosis of IgG4-RSD include lymphoplasmacytic infiltration with storiform fibrosis (Figure 3a), obliterative phlebitis or arteritis and lgG4 immunohistochemical staining demonstrating high ratio of lgG4-positive plasma cells to the overall number of plasma cells in tissue (Figure $3 b)$. A diffuse plasma-rich infiltrate with a ratio of lgG4 to $\lg$ greater than $50 \%$ and more than $30 \lg$ G4-positive cells per high-power field proves compelling when present with characteristic histopathological appearance. ${ }^{3}$ These histological and immunophenotypic features on a pathologic specimen when present are considered the 'gold standard' for diagnosis. ${ }^{3.4}$ Histolopathological features present with sarcoidosis include non-caseating granulomas irrespective of tissue type and therefore allow for a distinctive differentiation via biopsy.

Chronic sclerosing sialadenitis (Küttner's tumour) is a fibroinflammatory disease of the salivary gland with distinctive morphological appearance. However, when such inflammation is present with elevated tissue lgG4 infiltration, it is distinguished from other inflammatory diseases of the salivary glands and as such belongs to the spectrum of IgG4-related diseases (IgG4-RSD), thus complying with accepted guidelines as reported by many authors. ${ }^{1.5}$ Management of Küttner's tumours can be conservative, depending on the patient's symptoms. A 'watch and wait' approach is accepted where the patient is asymptomatic, comfortable and the lesion(s) are confirmed as being benign. ${ }^{6}$

$\lg G 4$ immunoglobulin is the rarest subtype of the $\lg G$ class, accounting for less than $6 \%$ of total IgG protein. When abnormal levels of lgG4 are found, they typically occur more frequently in middle-aged and older men, with a male to female ratio between $2: 1$ and $4: 1 .^{7-9}$ While serum levels can suggest the possible presence of $\operatorname{lgG} 4$, disease they are not diagnostic without histolopathological and immunohistochemical staining for lgG4.

The clinical significance of isolated elevations of serum IgG4 concentrations remains uncertain, ${ }^{3}$ with serum IgG4 concentrations normal in $30 \%$ of patients despite histopathological and immunohistochemical findings on biopsy. ${ }^{10}$ One source reports that IgG4 levels are elevated in $5 \%$ of the normal population. ${ }^{5}$ The most

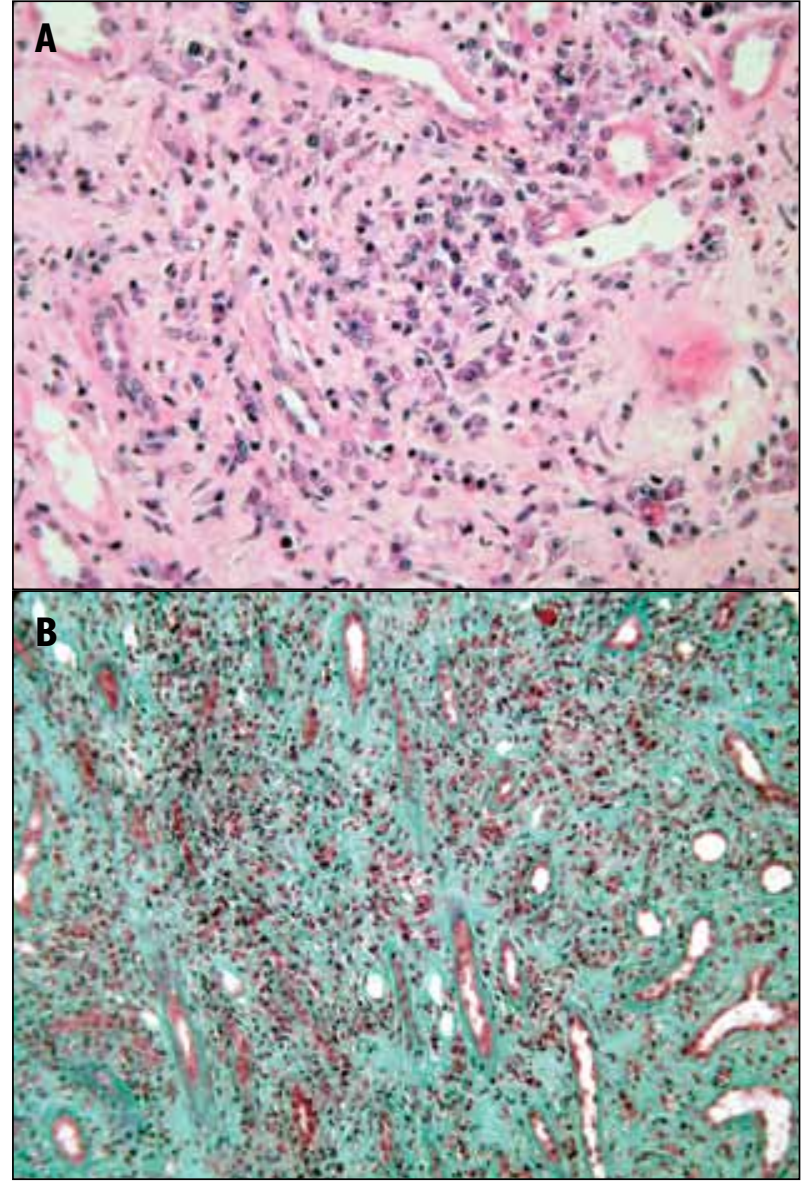

FIGURE 3 A: Hematoxylin and eosin stain: the lgG4 lymphoplasmacytic infiltrate has storiform fibrosis (circular pattern). B:Tubulointerstitial nephritis with sclerosis and plasma cell-rich infiltrate. Masson trichrome to show sclerosis and immunohistochemical stain for lgG4 to show lgG4 plasma cells.

common sites for lgG4 accumulation are the pancreas and lung. However, it may occur in other tissues, including the salivary glands, kidneys, hepatic portal tract, prostrate and retroperitoneal tissue.

Given the insidious presentation of $\lg G 4$ and the difficulty in correlating clinical findings, a diagnosis may only be reached with tissue sampling. Identifying sub-clinical disease in secondary organs can be challenging; cross-sectional imaging is effective in detecting any sub-clinical disease. Drawing a distinction between lgG4 disease and neoplastic disease is important. $\lg G 4$ is not a malignant disease and as such does not require treatments reserved for malignant conditions. No randomised control treatment trials have been conducted for IgG4-RSD to date. Treatment will be influenced by a patient's symptoms and depend on whether serious organ dysfunction is possible or imminent.

Reported cases of IgG4-RSD have adopted a 'watch and wait' approach for indolent and asymptomatic disease. However, lgG4 disease can lead to serious organ dysfunction; when required, an aggressive approach is recommended. Accepted first-line treatment is glucocorticoid, but no correlation has been found 
between the extent of disease and the required steroid treatment. ${ }^{3}$ In patients with confirmed IgG4-RSD who have a poor response to steroids, non-glucocorticoid options have been proposed including azathioprine, rituximab and mycophenolate mofetil, but the effects of these glucocorticoid-sparing medications in IgG4-RSD have not been evaluated adequately to clearly define their role relative to other agents.

Steroids (prednisolone) can be initiated at $0.6 \mathrm{mg} / \mathrm{kg}$ per day on a reducing dose subject to improvements evident through blood markers, symptomatic response or via cross-sectional imaging. Most patients respond favourably to steroid treatment within weeks, with reductions in the size of masses or organ enlargement and improvements in organ function with resolving symptoms. When starting treatment with steroids, clinical and hematological improvements can be rapid, as was observed with our patient following regular clinical appointments - a finding that is consistent with treatment of other reported lgG4 cases. ${ }^{1.6,9,11}$ To date, our patient remains symptom-free with almost normal renal function.

The natural history of IgG4-RSD has not been welldefined or understood, with clinical cases reporting some patients improving spontaneously without treatment. ${ }^{1,3,5}$ However, many patients have relapses. Infiltration of IgG4 immunoglobulins within an organ in addition to infiltration of other organs can lead to significant morbidity and mortality depending on the organs affected. This sometimes happens despite apparently effective treatment; therefore aggressive and persistent treatment may be needed.

No agreed criteria exist regarding the long-term treatment of this condition. As such, treatment requires adjustment,

\section{REFERENCES}

I Hamano H, Kawa S, Horiuchi A et al. High serum lgG4 concentrations in patient with sclerosing pancreatitis. N Engl J Med 200I, 344:732-38.

2 Cheuk W, Chan JK. IgG4-related sclerosing disease: a critical appraisal of an evolving clinicopathologic entity. Adv Anat Pathol 2010; 1 7:303-32.http://dx.doi.org/ I0.1097/PAP.0b0 I 3e3 I8I ee63ce

3 Stone JH, Zen Y, Deshpande V. IgG4-related disease. N Engl J Med 20I2; 366:539-5I. http://dx.doi.org/I 0. I056/NEJMra I I 04650

4 Geyer JT, Ferry JA, Harris NL et al. Chronic sclerosing sialadenitis (Küttner tumor) is an IgG4-associated disease. Am J Surg Pathol 20I0; 34:202-10. http://dx.doi.org/ I0.1097/PAS.0b0 I 3e3 I8I c8I lad

5 Ryu JH, Horie R, Sekiguchi $\mathrm{H}$ et al. Spectrum of disorders associated with elevated serum lgG4 levels encountered in clinical practice. Int J Rheumatol 2012;2012:232960. http://dx.doi.org/I0.I I55/20I2/232960

6 Kivernti E, Singh A, Clarke P. Küttner's tumour: an unusual cause of salivary gland enlargement. Hippokratia 2008; 12:56-8.

7 Raissian Y, Nasr SH, Larsen CP et al. Diagnosis of IgG4-related tubulointerstitial nephritis. J Am Soc Nephrol 20I I; 22:1343-52. http://dx.doi.org/I0.168I/ASN.20II010062

8 Nishikawa G,Nakamura K,YamadaY et al.Inflammatory pseudotumors of the kidney and the lung presenting as immunoglobulin G4-related disease: a case report. J Med Case Rep 20I I; 5:480. http://dx.doi. org/I0.II86/I752-1947-5-480 with tapering of steroids after three to six months and a low dose maintained over periods up to three years. ${ }^{3}$ While IgG4 is a non-malignant condition, several types of lymphoma have been reported to date in patients with IgG4-RD in both Japan and North America. ${ }^{12-14}$ Despite these publications, there is to date no confirmed risk attributed to developing cancer with IgG4-RSD and the risk of malignancy in patients with IgG4-RSD requires further study.

\section{CONCLUSION}

An unusual case of lgG4-related systemic disease has been described following its initial presentation as a submandibular neck mass with local lymphadenopathy. With no immunohistochemical staining on the initial salivary biopsy, a cause was not established for the salivary gland enlargement, but conservative treatment was taken following a benign biopsy. Secondary infiltration to renal tissue resulted in tubulointerstitial nephritis. This condition responded well to treatment with steroids.

Following a diagnosis of lgG4-RSD clinicians should carefully consider clinical history and physical examination, paying particular attention to salivary glands (submandibular or parotid enlargement), biliary tree, pancreas and eyes (lacrimal gland enlargement, orbital pseudotumour). IgG4-RSD is a condition that most often occurs in middle-aged and older men. It can be a collection of disorders that share specific pathological, serological and clinical features. While this case highlights an example of an uncommon disease, it encourages medical practitioners to be mindful of the variety of delayed clinical presentations exhibited in IgG4 disease, its potential to mimic several conditions and the good clinical response that typically results in steroid treatment.

9 Shoji S, Nakano M, UsuiY: IgG4-related inflammatory pseudotumor of the kidney. Intern J Urol 20I0; 17:387-8.

10 Sah RP, Chari ST. Serologic issues in IgG4-related systemic disease and autoimmune pancreatitis. Curr Opin Rheumatol 201 I; 23:10813. http://dx.doi.org//0.1097/BOR.0b0I3e32834/3469

I I Cornell LD, Chicano SL, Deshpande V et al. Pseudotumors due to lgG4 immune-complex tubulointerstitial nephritis associated with autoimmune pancreatocentric disease. Am J Surg Pathol 2007; 31:1586-97.

12 Sato Y, Ohshima K, Ichimura K et al. Ocular adnexal IgG4-related disease has uniform clinicopathology. Pathol Int 2008; 58:465. http://dx.doi.org/I0.I I I I/j.I440-I827.2008.02257.x

I3 Takahashi N, Ghazale AH, Smyrk TC et al. Possible association between IgG4-associated systemic disease with or without autoimmune pancreatitis and non-Hodgkin lymphoma. Pancreas 2009; 38:523. http://dx.doi.org/I0.1097/MPA.0b0 I3e3I8I9d73ca

14 Cheuk W, Yuen HK, Chan AC et al. Ocular adnexal lymphoma associated with IgG4+ chronic sclerosing dacryoadenitis: a previously undescribed complication of lgG4-related sclerosing disease. Am J Surg Pathol 2008; 32:II59-67. http://dx.doi. org/10.1097/PAS.0b013e31816148ad 